\title{
The Salle Pleyel, Paris, and Architectural Acoustics
}

THE meetings of the Second International Con- acoustics both of the Great Hall, where the in. 1 gress of Electricity, recently held in Paris, augural and other meetings were held, and of took place in the great building newly constructed the so-called Salle Chopin, where the meetings of

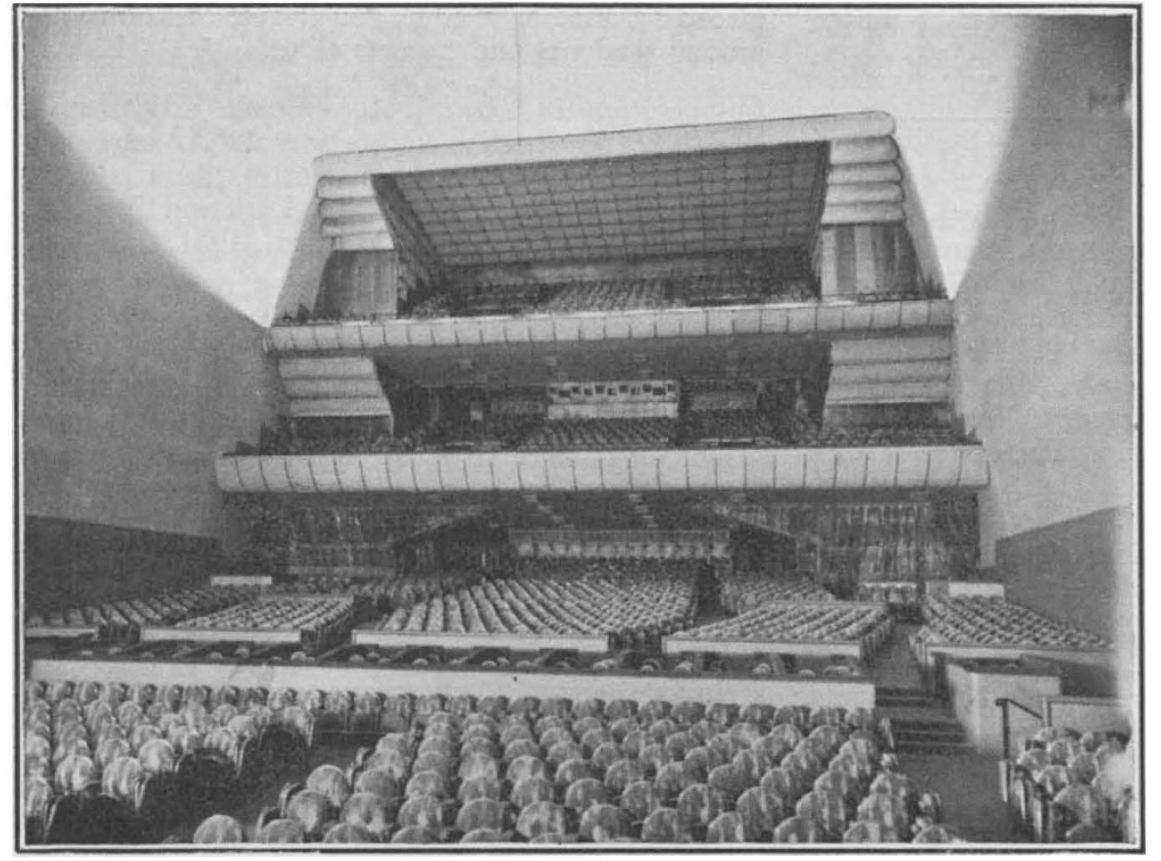

Pholo?

Fig. 1.-Auditorium of the Salle Pleyel, seen from the stage.

iOhonojon

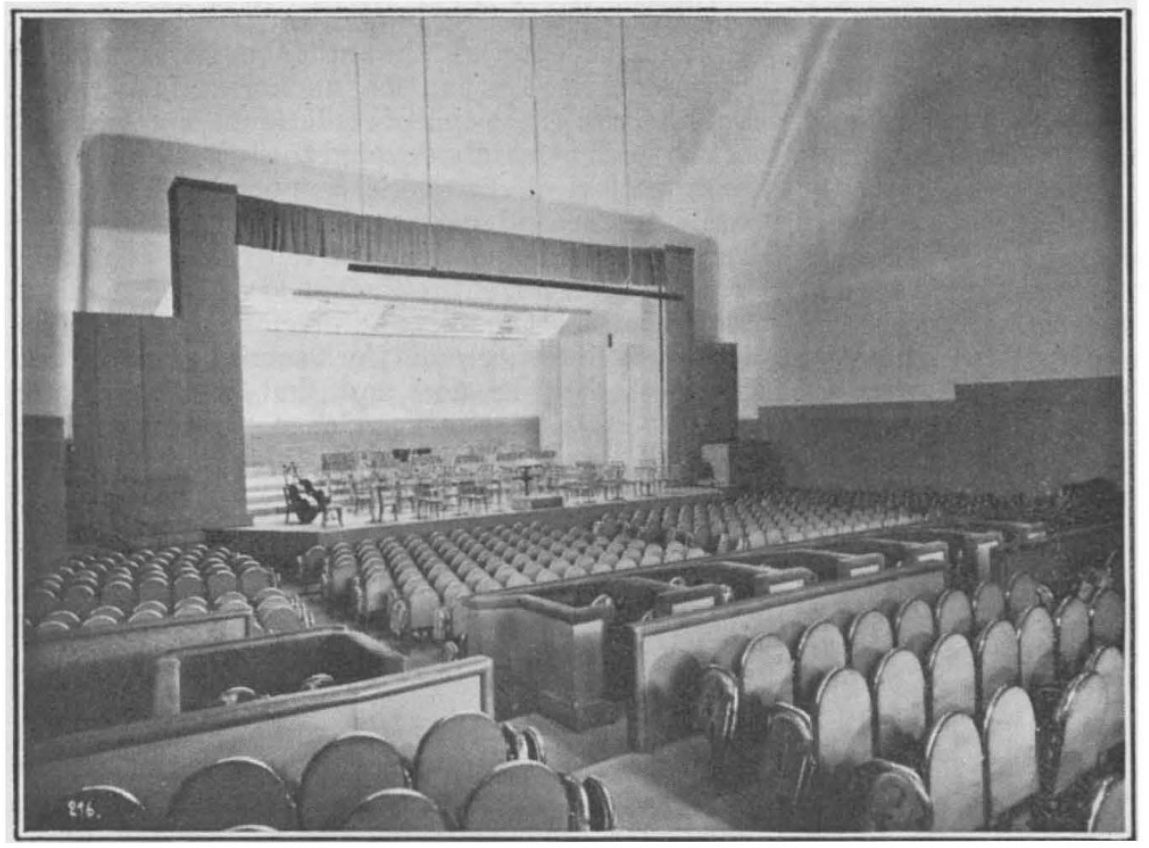

Fit. 2.-Stage of the Salle Pleyel, seen from about the middle of the parterre.

Section 1, devoted to pure physics, occurred. The Great Hall can accommo. date some three thousand auditors, and yet, as the present writer proved, a speaker reading from a paper in the ordinary tone of a lecturer in a small class-room can be heard perfectly in various parts of the hall, includ. ing the back of the upper gallery, more than fifty yards away. The principles upon which this hall was designed by $\mathbf{M}$. Gustave Lyon are very simple, but there is no doubt as to their efficacy in this and other examples of his work.

The reflections which take place at the walls of a hall are absolutely necessary for good hearing, since without reinforcement of this kind a normal speaking voice is inaudible at a very short distance. A curious experiment was carried out by $M$. Lyon on this point at Challais - Meudon. Two observers were suspended by cords below small balloons, which could be manoeuvred to any desired distance apart, and it was found that, under such conditions, the speak. ing voice was quite inaud. ible at a distance of 11 metres. Similar results have been obtained on plains covered with soft new-fallen snow, which is a very bad reflector of sound, while, on the other hand, on perfectly smooth water at night a normal voice can be heard at a distance of more than a mile. Reflections are, then, indispensable.

On the other hand, if the interval between the

by the Pleyel Company in the faubourg Saint Honoré, and there are probably few among those present who were not impressed by the faultless reception of the direct and of the reflected sound is too large, an unpleasant effect is produced which with increasing interval soon resolves itself into

No. 3279 , VoL. 130] 
two distinct sounds. Estimates of the maximum permissible interval naturally vary somewhat. According to Ernst Petzold, it should not exceed $\frac{1}{20}$ sec. M. Lyon has carried out extensive experiments with trained musicians as his collaborators, and finds that a slightly longer interval may be

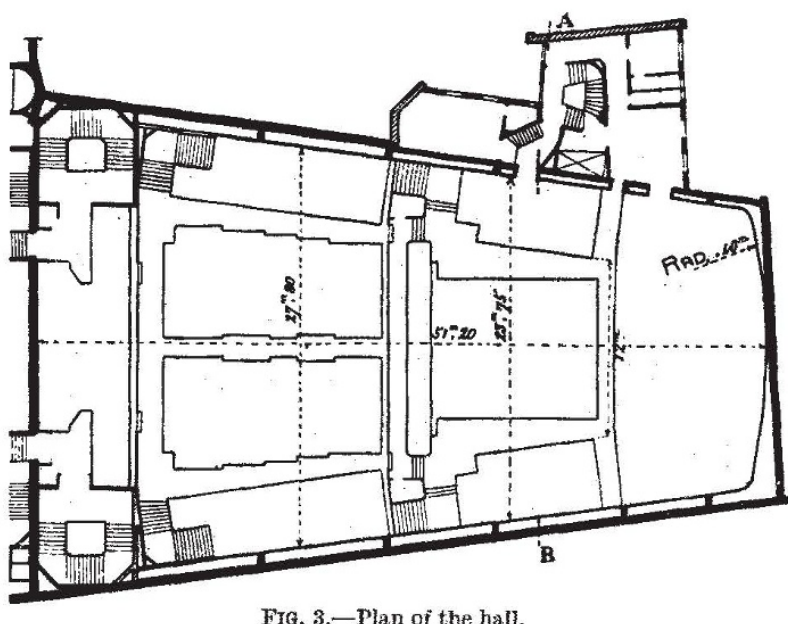

allowed in practice. The least permissible interval is greater with such sounds as those of an orchestra than with staccato sounds, such as the noise of castanets or of an actor dying in the prescribed mode, and appears to run up to $\frac{1}{10}$ sec. for the former, but not to exceed $\frac{x}{15}$ sec. for the latter. In any event, $\frac{1}{15}$ sec, or, expressed as sound path, 23 metres, may be taken as a practical limit to which to work. This at once restricts the depth of the stage to 11 metres, if good reflection from the back wall is taking place, and, for the sake of listeners to one side, the breadth to 23 metres, if the whole stage is to be occupied by, for example, an orchestra. The stage in the Salle Pleyel is actually about 20 metres wide by 10 metres deep.

A hall is bounded by floor, ceiling, wall at back of stage (which we will call stage wall), side walls, and wall opposite stage (which we will call back wall). Any hall for a large audience will be much more than 11 metres long, which means that any echo from the back will make, for people near the stage, more than the permissible interval with the direct sound. Such echoes should therefore be completely suppressed. In the Salle Pleyel, this is effected by treatment with a special sound-absorbing material applied to curved surfaces, the general arrangement of which is clear, without lengthy description, from Fig. 1. The floor, with its padded seats, is a very bad reflector, and in any event waves reflected from it will strike the back wall and be absorbed. The side walls, as can be seen from Fig. 3, are thrown back so as to make an acute angle at the stage end. This allows a larger capacity than if they were parallel, and also ensures, as can be seen, that no reflection from the side walls can, with respect to the direct sound, lead to an interval exceeding the allowable limit. There remain the stage wall and ceiling, which are treated as essential reflectors, in the following manner.

The stage wall, $A B$ in Fig. 4, has its vertical pro- file in the form of a circle, inclined so as to throw the sound over the whole parterre, and is 7 metres high. The distance $S A$ is about 10 metres, so that, with this height, the interval between direct and reflected wave does not exceed $\frac{1}{15}$ sec. If $A B$ were much higher, this condition would not be satisfied. The horizontal profile is likewise approximately circular, as shown in Fig. 3. The first part of what may be called the ceiling is the reflector $B C$, designed to throw the sound into the first gallery. The vertical distance between $B$ and $C$ is likewise 7 metres, and the interval condition is satisfied, as it is by the third reflector $C D$ which completes the covering of the hall, and throws the sound into the second gallery. The harmonious appearance of the curves is shown by Fig. 2, which is a view of the stage from the middle of the hall, behind the row of boxes. The excellence of the hearing, even from the back of the second gallery, has already been mentioned.

The Pleyel building contains, besides the two smaller halls, of excellent acoustics, many other features of interest to the physicist no less than to the musician. There are a large number of absolutely sound-proof studios, each of which is a room of light construction; the whole weight of this room rests on a layer of sound-proof material, spread on the floor of a slightly larger enclosing room which forms part of the main structure. No conductor of sound, such as a nail or screw, connects the interior room with the framework of the building. The interior room has its own separate windows, opposite those of the main building. Here again the effectiveness of the design is astonishing, the most muscular piano-playing in one studio being completely inaudible in the next.

M. Gustave Lyon's very simple principles have found, perhaps, their most striking exposition in

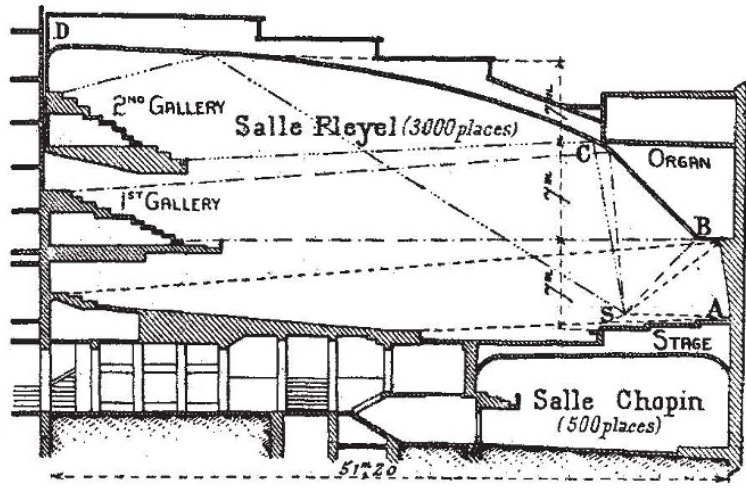

FIG. 4.-Vertical section of the hall.

the Great Hall, but he has behind him a series of remarkable achievements in the way of remedying, at small cost, the bad acoustics of certain halls, of which the best-known example is, perhaps, the hall of the Trocadéro at Paris, once notorious for its execrable sound properties, but now extremely satisfactory. His work is an excellent example of how far a little sound physics can be made to go in the hands of a man of bold originality and energy, who makes experiment and experience his guides.
E. N. Da C. Andrade.

No. 3279 , VoL. 130 ] 